\title{
Curcumin-mediated bone marrow mesenchymal stem cell sheets create a favorable immune microenvironment for adult full-thickness cutaneous wound healing
}

Zhi Yang ${ }^{1}$, Chengmin $\mathrm{He}^{1}$, Jinyang $\mathrm{He}^{2}$, Jing $\mathrm{Chu}^{1}$, Hanping $\mathrm{Liu}^{1 *}$ and Xiaoyuan Deng ${ }^{1 *}$ (D)

\begin{abstract}
Background: Adult full-thickness cutaneous wound repair suffers from an imbalanced immune response, leading to nonfunctional reconstructed tissue and fibrosis. Although various treatments have been reported, the immunemediated tissue regeneration driven by biomaterial offers an attractive regenerative strategy for damaged tissue repair.

Methods: In this research, we investigated a specific bone marrow-derived mesenchymal stem cell (BMSC) sheet that was induced by the Traditional Chinese Medicine curcumin (CS-C) and its immunomodulatory effects on wound repair. Comparisons were made with the BMSC sheet induced without curcumin (CS-N) and control (saline).

Results: In vitro cultured BMSC sheets (CS-C) showed that curcumin promoted the proliferation of BMSCs and modified the features of produced extracellular matrix (ECM) secreted by BMSCs, especially the contents of ECM structural proteins such as fibronectin (FN) and collagen I and III, as well as the ratio of collagen III/I. Two-photon fluorescence (TPF) and second-harmonic generation (SHG) imaging of mouse implantation revealed superior engraftment of BMSCs, maintained for 35 days in the CS-C group. Most importantly, CS-C created a favorable immune microenvironment. The chemokine stromal cell-derived factor 1 (SDF1) was abundantly produced by CS-C, thus facilitating a mass migration of leukocytes from which significantly increased expression of signature $T_{H} 1$ cells (interferon gamma) and M1 macrophages (tumor necrosis factor alpha) genes were confirmed at 7 days postoperation. The number of $\mathrm{T}_{H} 1$ cells and associated pro-inflammatory $\mathrm{M} 1$ macrophages subsequently decreased sharply after 14 days post-operation, suggesting a rapid type I immune regression. Furthermore, the CS-C group showed an increased trend towards M2 macrophage polarization in the early phase. CS-C led to an epidermal thickness and collagen deposition that was closer to that of normal skin.
\end{abstract}

Conclusions: Curcumin has a good regulatory effect on BMSCS and this promising CS-C biomaterial creates a proregenerative immune microenvironment for cutaneous wound healing.

Keywords: Curcumin, Bone marrow mesenchymal stem cell, Cell sheet, Immune response, Cutaneous wound healing

\footnotetext{
* Correspondence: liuhp@scnu.edu.cn; xydeng12@126.com

${ }^{1}$ MOE Key Laboratory of Laser Life Science, College of Biophotonics, South China Normal University, No. 55 Zhongshan Avenue West, Tianhe District, Guangzhou 510631, China

Full list of author information is available at the end of the article
} 


\section{Background}

Adult full-thickness cutaneous wounds, caused by burning, mechanical injury, or chronic ulcers, and so forth, usually lead to a non-functional tissue known as a scar $[1,2]$. Wound healing is a complex biological process in which the immune response plays a vital role in host defense, necrotic cell clearance, and tissue regeneration. Indeed, a dysregulated immune response can lead to the development of pathological fibrosis or scarring, even impairing normal tissue function and ultimately leading to restoration failure [3]. The most conspicuous and often-reported feature of chronic inflammatory is the persistent presence of elevated levels of pro-inflammatory cytokines, such as tumor necrosis factor (TNF)- $\alpha$, interleukin (IL)-1 $\beta$, and IL- 6 , secreted by type I immune cells ( $\mathrm{T}_{\mathrm{H}} 1$ cells) and associated pro-inflammatory M1 macrophages [4]. However, the depletion of macrophages in early immune injury leads to failures in matrix degradation during tissue repair [5]. In contrast, the last decade has seen the opposite side of the immune response, showing that a suitable immune response can be an effective strategy for promoting tissue regeneration [6]. Tissuerepairing M2 macrophages possess anti-inflammatory properties and support the functions of $\mathrm{T}$ helper $2\left(\mathrm{~T}_{\mathrm{H}} 2\right)$ associated effector cells [7]. These two types of cells work together to promote tissue repair by expressing several wound healing factors such as arginase, platelet-derived growth factor (PDGF), vascular endothelial growth factor (VEGF) $\alpha$, and insulin-like growth factor (IGF) [8-10].

Immune mediation driven by biomaterial is regarded as an innovative tissue regenerative strategy. There have been numerous attempts to seek promising biomaterials to improve cutaneous wound healing. Bone marrowderived mesenchymal stem cells (BMSCs), based on their key roles during the wound healing process, are considered an attractive therapeutic biomaterial $[11,12]$ and exhibit excellent potential for reconstituting tissue due to their self-renewal ability, differentiation into various cell lineages, and secretion of paracrine factors [13]. More importantly, investigations in the past few years have provided new insight into the function of BMSCs during immune response in tissue repair. The immunoregulatory properties of BMSCs are appealing for their ability to inhibit $\mathrm{T}$-cell differentiation into $\mathrm{T}_{\mathrm{H}} 1$ cells and the switch of macrophages from a pro-inflammatory type 1 (M1) to an anti-inflammatory type 2 (M2) phenotype [14-16]. However, therapies based on stem cells alone limit their functions and effectiveness in the clinic. The administration of BMSCs by intravenous injection or topical delivery results in a low delivery number or survival rate in the wound site due to enzymatic digestion of the single cell suspension in vitro and the lack of an appropriate carrier to protect BMSCs in the wound area [17].
BMSC sheet technology has emerged as an attractive approach that has been applied in many clinical treatments, such as wound healing, periodontal-like tissue regeneration, cardiac healing, and osseointegration [18-22]. Prolonged cultivation and protection against enzyme digestion allows increased cell numbers and long-term viability. Moreover, the BMSC sheet can provide an intact biomaterial consisting of cultured cells and secreted cytokines, along with natively deposited extracellular matrix (ECM). Through an intricate understanding of wound biology that has been developed by researchers over past decade, the importance of the ECM has been fully recognized. Far beyond acting only as a structural support, the ECM provides cells with a dynamic biophysical, biomechanical, and biochemical niche, and exerts tailored biological activities on cells to manipulate their behaviors [23].

Inspired by the immunoregulatory properties of BMSCs and the procedures of constituting an intact BMSC sheet (inducing BMSCs to secret a vast number of biological cytokines and produce native ECM), we envisage that by effectively mediating BMSCs to selectively secrete cytokines and produce specified endogenous ECM, a new biomaterial capable of regulating the immune response could be established and could promote wound healing. Some molecules have regulatory functions for directing the behavior of BMSCs. Traditional Chinese Medicine (TCM) can activate cells for wound regeneration through adjuvants derived from their ingredients [24]. Mounting evidence has shown that TCM as a novel therapeutic material has a powerful therapeutic effect on many types of wound healing, such as periodontal ligament defects and chronic ulcers, among others $[25,26]$. Curcumin, the extract of zingiberaceae roots, has been widely used as a medicine for various diseases for many centuries. Curcumin exhibits a broad range of wound healing properties, such as anti-oxidant, anti-inflammatory, anti-infective, and anti-fibrosis effects [27-29]. Therefore, curcumin was initiated as a regulatory molecule to mediate BMSCs to produce a new, specific type of BMSC sheet. In this research, we focused on investigating the functional role of curcumin, particularly its ability to regulate BMSC behavior and ECM production, and hence to create a favorable immune microenvironment for adult full-thickness cutaneous wound healing.

\section{Methods}

\section{Ethics statement}

All experimental protocols were approved by the Ethical Committee for Animal Experiments of South China Normal University. All animal experiments conducted in this research were performed in accordance with the guidelines of South China Normal University Intramural 
Animal Use and Care Committee and met the NIH guidelines for the care and use of laboratory animals.

\section{Experimental animals}

Four-week-old green fluorescent protein $(\mathrm{GFP})^{+} \mathrm{C} 57 \mathrm{BL} /$ 6 mice purchased from Cyagen Biosciences (Guangzhou, China) were used for culturing BMSCs and BMSC sheets. Ten-week-old male BALB/c mice were purchased from the Experimental Animal Center of Southern Medical University (Guangzhou, China).

To evaluate the effects of curcumin on the quality of wound repair, mice were randomly assigned to three different treatment groups. The control group received saline. The BMSC-curcumin sheet group (CS-C) received the BMSC sheet induced with curcumin applied to the affected area. The BMSC sheet group (CS-N) received the BMSC sheet induced without curcumin applied to the affected area. All mice were housed under pathogenfree conditions $\left(22{ }^{\circ} \mathrm{C}, 12\right.$-h light/12-h dark cycles and $50-55 \%$ humidity) with proper food and water. All surgical procedures were performed under general anesthesia via an intraperitoneal injection of $1 \%$ pentobarbital.

\section{Construction of BMSC sheets and induction with curcumin}

$\mathrm{GFP}^{+}$BMSCs were obtained as previously reported by our group [30]. BMSC sheets were prepared by plating $1.5 \times 10^{5}$ of third passage cells on culture dishes (six-well plates, Corning). BMSC sheets were cultured in OriCell ${ }^{\mathrm{TM}}$ mouse MSC Growth Medium (MUCMX-90011, Cyagen Biosciences, Inc.) with $100 \mathrm{mg} / \mathrm{mL}$ vitamin $\mathrm{C}$ in a humidified incubator (Thermo Scientific Forma 3110, Thermo Fisher Scientific, Inc.) at $37{ }^{\circ} \mathrm{C}$ with $5 \% \mathrm{CO}_{2}$. The experimental group was additionally subjected to $0.5 \mu \mathrm{M}$ curcumin throughout the entire incubation stage. The culture medium was changed every 2 days. The culture was then continued for 12 days until a white membrane structure could be observed and could be detached intact from the substratum using a cell scraper (Biologix, Angfei Biosciences, Inc.).

\section{Scanning electron microscopy (SEM) imaging of BMSC sheets}

CS-N and CS-C were first fixed in $2.5 \%$ glutaraldehyde at $4{ }^{\circ} \mathrm{C}$ for $4 \mathrm{~h}$. They were then cleaned four to six times in $0.1 \%$ phosphate buffer and dehydrated in a gradient of alcohol concentrations (30\%, 50\%, 70\%, 90\%, 100\%). Finally, the samples were freeze-dried and sputter-coated with a 30-nm gold layer. SEM images are obtained using a scanning electron microscope (Zeiss Ultra 55, Carl Zeiss, Jena, Germany). The arrangement of cells and collagen was clearly visible.

\section{Wound model and surgical procedure}

Ten-week-old male BALB/c mice were anesthetized with an intraperitoneal injection of pelltobarbitalum natricum. The hair on the dorsal skin of the mice was shaved and removed and the bared skin was sterilized with $75 \%$ alcohol. A full-thickness, 7-mm diameter skin wound was produced using a biopsy punch. A CS-C sheet, CS$\mathrm{N}$ sheet, or saline (control) was then placed on the wound site (depending on the group assigned). Finally, the wound area was covered with Comfeel transparent dressing (Coloplast, Beijing, China) and wrapped with medical adhesive tape.

\section{Histological and immunofluorescence analysis}

The wound bed tissues were harvested at 3, 7, 14, 21, and 28 days after surgery, and the two cell sheet group tissues were fixed with $4 \%$ paraformaldehyde and then embedded in paraffin and cut into 5-mm thick longitudinal sections. The sections were subjected to hematoxylin and eosin (H\&E) staining for histological analysis of wound regeneration. In addition, Masson staining was carried out to reveal the collagen accumulation state. For immunofluorescence staining, to investigate the in vivo immune reaction of curcumin treatment in the different groups, anti-CD45, anti-CD11c, anti-IFN- $\gamma$, anti-Relm $\alpha$, antiSDF1, anti-TGF $\beta$, and anti-IL1RN antibodies (Abcam) were used to identify lymphocytes, $M 1$ macrophages, $\mathrm{T}_{\mathrm{H}} 1$ cells, M2 macrophages, stromal cell-derived factor 1 $(\mathrm{SDF} 1)^{+}$cells, transforming growth factor (TGF) $\beta$, and IL1 receptor antagonist (IL1RN). To investigate the contents of the cell sheets, sections were incubated with antibodies against type I collagen (Col-I, 1:50, Abcam) and type III collagen (Col-III, 1:80, Abcam). Secondary antibodies were goat anti-rabbit IgG (Alex Fluor488 conjugated, 1:200, CST) and goat anti-rat IgG (Alex Fluor555 conjugated, 1:500, CST). All data were analyzed using ImageJ software.

\section{Real-time polymerase chain reaction (RT-PCR) analysis}

Total RNA from newly formed tissue was isolated with TRIzol Reagent (TaKaRa, Dalian, China). The samples were then used for cDNA synthesis using the PrimeScript ${ }^{\oplus}$ RT reagent Kit with gDNA Eraser (TaKaRa, Dalian, China), and real-time PCR was carried out according to the manufacturer's instructions (Applied Biosystems 7500) with $\mathrm{SYBR}^{\oplus}$ Premix Ex Taq II (TaKaRa, Dalian, China). The primer sequences for each gene are described in Table 1. All genes were assessed using the $2^{-\Delta \Delta C t}$ method.

\section{DNA amplification and sequencing}

To determine the $\mathrm{GFP}^{+}$cell activity and quantity in vivo, skin samples were harvested at $0,21,28$, and 35 days after surgery. Total DNA from the samples was isolated with the TIANamp Genomic DNA kit (DP130227, 
Table 1 Primers used for real-time polymerase chain reaction

\begin{tabular}{|c|c|}
\hline Gene & Primer sequence \\
\hline \multirow[t]{2}{*}{ Col-1 } & Forward 5'- AAGAAGACATCCCTGAAGTCA -3' \\
\hline & Reverse 5'- GCAGATACAGATCAAGCATACC -3' \\
\hline \multirow[t]{2}{*}{$\mathrm{Col}-3$} & Forward 5'- GCAAGGCAATGAGACTACC -3' \\
\hline & Reverse 5'- CCAATGTCCACACCAAATTC -3' \\
\hline \multirow[t]{2}{*}{$\|-4$} & Forward 5'- CTAGTTGTCATCCTGCTCTTCT -3' \\
\hline & Reverse 5'- CTTCTCCTGTGACCTCGTTC -3' \\
\hline \multirow[t]{2}{*}{ Tnfa } & Forward 5'- AGGTTCTCTTCAAGGGACAA -3' \\
\hline & Reverse 5'- CCTGGTATGAGATAGCAAATCG -3' \\
\hline \multirow[t]{2}{*}{ Ifny } & Forward 5'- ATGAACGCTACACACTGC - $3^{\prime}$ \\
\hline & Reverse 5'- CCACATCTATGCCACTTGAG -3' \\
\hline \multirow[t]{2}{*}{ Relma } & Forward 5'- TACTGGGTGTGCTTGTGGCTITGC -3' \\
\hline & Reverse 5'- GGCAGTGGTCCAGTCAACGAGTAAG -3' \\
\hline \multirow[t]{2}{*}{ Actin $\beta$} & Forward 5'- CGTTGACATCCGTAAAGACC -3' \\
\hline & Reverse 5'- TAGGAGCCAGAGCAGTAATC - $3^{\prime}$ \\
\hline \multirow[t]{2}{*}{ Cxcr4 } & Forward 5'- CTCCTCCTGACTATACCTGAC-3' \\
\hline & Reverse 5'- CGAGACCCACCATTATATGC -3' \\
\hline \multirow[t]{2}{*}{$\operatorname{Tg} f \beta$} & Forward 5'- CTGCTGACCCCCACTGATAC - $3^{\prime}$ \\
\hline & Reverse 5'- AGCCCTGTATTCCGTCTCCT -3' \\
\hline \multirow[t]{2}{*}{$\operatorname{ILIRN}$} & Forward 5'- ACCTTCATAGTGTGTTCTTGG -3' \\
\hline & Reverse 5'- CTTCTTCTITGTTCTTGCTCAG -3' \\
\hline \multirow[t]{2}{*}{$\operatorname{Arg} 1$} & Forward 5'- GAAGAATGGAAGAGTCAGTGTG -3' \\
\hline & Reverse 5'- GGAGTGTTGATGTCAGTGTG -3' \\
\hline \multirow[t]{2}{*}{$\operatorname{Jag} 2$} & Forward 5'- GTGTGGTTATCTGCGTATGG -3' \\
\hline & Reverse 5'- GTTGCGGATGGGATTGAG -3' \\
\hline \multirow[t]{2}{*}{ iNOS } & Forward 5'- CCTATCTCCATTCTACTACTACCA G -3' \\
\hline & Reverse 5'- ACCACTTTCACCAAGACTCTA -3' \\
\hline \multirow[t]{2}{*}{$\operatorname{Tb} \times 21$} & Forward 5'- CGCATCTGTTGATACGAGTG -3' \\
\hline & Reverse 5'- TGGTTGGATAGAAGAGGTGAG -3' \\
\hline
\end{tabular}

TIANGEN Biotech, Beijing, China). The DNA was then amplified using TaKaRa Ex Taq ${ }^{\circ}$ (TaKaRa, Dalian, China), including $0.25 \mu \mathrm{L}$ TaKaRa Ex Taq $(5 \mathrm{U} / \mu \mathrm{L}), 4.0$ $\mu \mathrm{L}$ dNTP mixture, $5 \mu \mathrm{L} 10 \times$ Ex Taq buffer $\left(\mathrm{Mg}^{2+}\right.$ Plus, $2.0 \mu \mathrm{L}$ template DNA, $3.0 \mu \mathrm{L}$ each of upstream and downstream primers, and $32.75 \mu \mathrm{L}$ sterile distilled water). The GFP primer sequences were: forward 5'GAAGAACGGCATCAAGGT-3', reverse 5'-GCTCAGG TAGTGGTTGTC-3'. After obtaining the DNA amplification products, the products were sent to Meiji biological company (Shanghai, China) for sequencing.

\section{Intravital imaging of BMSC sheets transplanted into the wound site ex vivo}

To evaluate the $\mathrm{GFP}^{+}$cell activity and trace the cells of the GFP-BMSC-sheets in vivo, second-harmonic generation (SHG) imaging and two-photon fluorescence (TPF) imaging with a commercial LSM 710 NLO confocal microscope (Zeiss, Jane, Germany) was conducted. The whole process is quick so that the samples remain alive. The process captures a three-dimensional image using the stack scan mode.

\section{Flow cytometry}

To explore the effects of curcumin on cell proliferation, the curcumin treatment group was analyzed at 1, 3, 6, and 9 days. Flow cytometry was performed using a BD LSRFortessa, and flow cytometry data were analyzed using Modifit software. Collected BMSCs $(800 \mathrm{rpm} / \mathrm{min})$ were washed once with $1 \mathrm{~mL}$ phosphate-buffered saline (PBS), followed by the addition of $500 \mu \mathrm{L}$ PBS containing $50 \mu \mathrm{g} / \mathrm{mL}$ ethidium bromide (PI) and $100 \mu \mathrm{g} / \mathrm{mL}$ RNase A; they were then incubated at $4{ }^{\circ} \mathrm{C}$ avoiding light for $20 \mathrm{~min}$. Under a standard program, the excitation wavelength was $488 \mathrm{~nm}$, and 1000-2000 cells were counted.

\section{Cell migration assay in vitro}

The chemotaxis of macrophages was measured in a 24well transwell culture chamber with an $8.0-\mu \mathrm{m}$ pore polycarbonate membrane insert (Corning, USA). The control group, CS-N group, and CS-C group were placed in the lower chamber to investigate the chemotactic capacity of macrophages. Macrophages (RAW 264.7, BNCC) were seeded at $10^{6}$ per well in the upper chamber. After co-incubation for 24 and $48 \mathrm{~h}$, the polycarbonate membrane was fixed in $4 \%$ paraformaldehyde and then stained with crystal violet solution. The number of migrated macrophages was counted with an optical microscope (Mingmei, Shenzhen, China). Five views of each sample were counted, and each group was evaluated four times.

\section{AMD3100 injection experiment}

AMD3100 (Sigma-Aldrich, St Louis, MO) was subcutaneously injected to the wound area of receptor mice; 8 mg of AMD3100 per kilogram of body weight per day.

\section{Statistical analyses}

Statistical analyses were performed using a statistical software package (GraphPad Prism 7.0). The unpaired two-tailed $t$ test or one-way analysis of variance (ANOVA) were used to assess statistical significance. $P$ values of 0.05 or less were considered significant.

\section{Results}

\section{Characterization of the BMSC sheet}

Third passage BMSCs were cultured in six-well plates with OriCell ${ }^{\mathrm{Tm}}$ mouse BMSC Growth Medium supplemented with $0.5 \mu \mathrm{M}$ curcumin and $100 \mathrm{mg} / \mathrm{mL}$ vitamin C. Up to the twelfth day, a white layer of cell membrane was observed (Fig. 1a). The macroscopic shape of this 

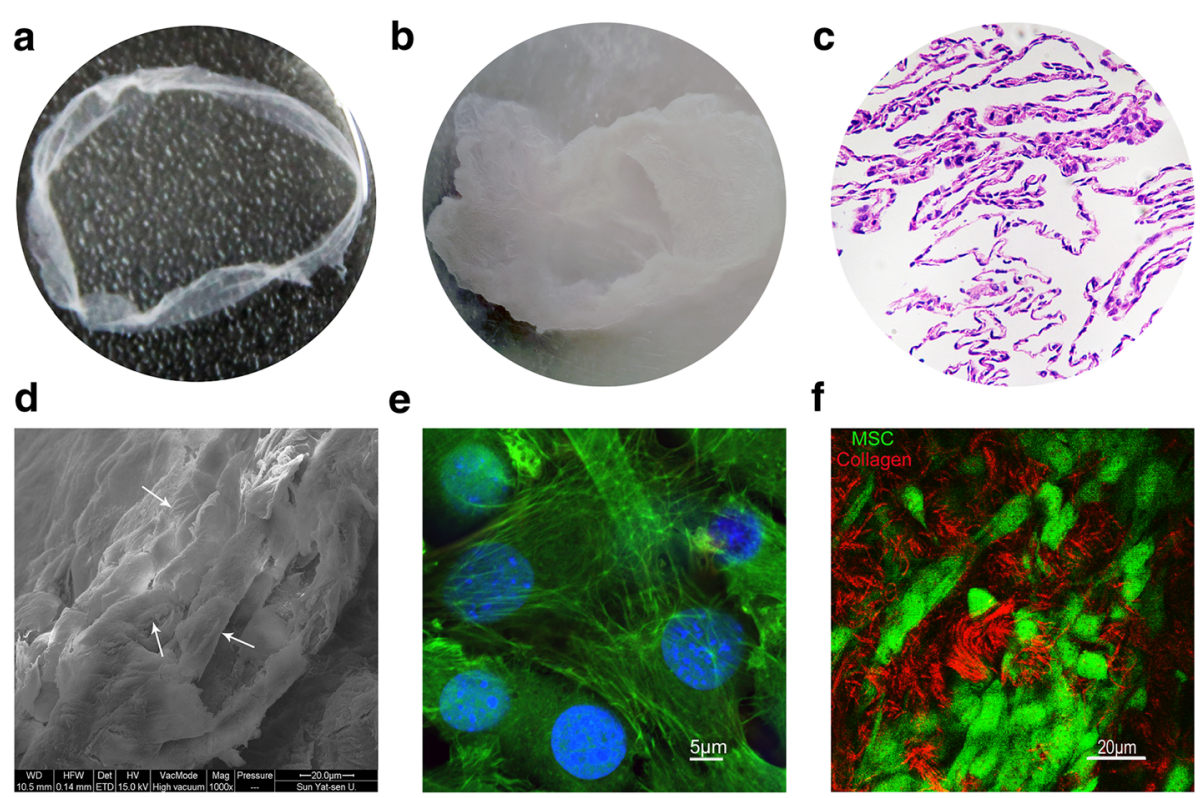

f

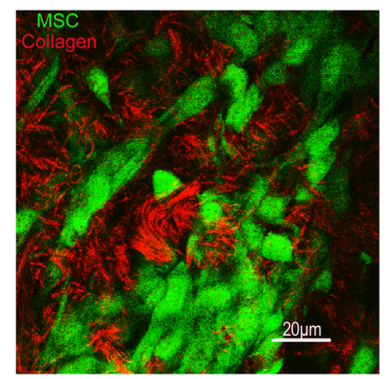

Fig. 1 Characterization of the BMSC sheet. a The appearance of the BMSC sheet (6 cm in diameter). b Stereomicroscope image of the BMSC sheet (5X). $\mathbf{c}$ H\&E staining of BMSC sheets which contained many layers of cells. $\mathbf{d}$ Scanning electron microscope image of the BMSC sheet; the arrows point to mesenchymal stem cells (MSCs) $(1 \mathrm{kx}, 20 \mu \mathrm{m})$. e Fluorescence microscope image of the BMSC sheet; green and blue show the cytoskeleton of GFP+ BMSCs and cell nuclei, respectively $(63 \times, 5 \mu \mathrm{m})$. $\mathbf{f}$ Second harmonic imaging (SHG) image of the BMSC sheet; red and green represent collagen and cells, respectively $(40 \times, 20 \mu \mathrm{m})$

cell sheet was observed using a stereomicroscope (Fig. 1b) and exhibited a certain thickness and flexibility. $\mathrm{H} \& \mathrm{E}$ staining revealed that the cell aggregate in the curcumin-stimulated group (CS-C) was a membranous structure composed of collagen containing buried BMSCs (Fig. 1c). The SEM image revealed numerous $\mathrm{GFP}^{+}$BMSCs in the sheet, which stacked together with extension of the culture time (Fig. 1d). These BMSCs presented spindles under green fluorescence using a confocal microscope (Fig. 1e). The special structure of the BMSC sheet was demonstrated by SHG, in which many BMSC layers surrounded bundles of collagen and some BMSCs were on the collagen surface, some were under the collagen, and some were interspersed between the collagen (Fig. 1f).

\section{Influence of curcumin on BMSC proliferation activity}

As discussed above, small molecules have a strong impact on cellular activity. The activity of BMSCs was also greatly enhanced after the application of $0.5 \mu \mathrm{M}$ curcumin (Fig. 2a-d). Because the formation of BMSC sheets requires 12 days, the growth rate of the cells gradually decreased during the process. However, this decline could be relieved by curcumin (Fig. 2e). A greater number of BMSCs were in the S, G2, and M period after curcumin treatment. Additionally, the number of active cells increased significantly by $4.63 \%, 9.51 \%, 41.09 \%$, and $35.78 \%$, respectively, after $1,3,6$, and 9 days of exposure to curcumin (Fig. 2f). Also, the CS-C sheet showed increased expression of the cell proliferation marker Ki67 than that of the CS-N sheet, suggesting a promotion ability of curcumin on BMSC proliferation (Fig. 2g, h).

\section{Engraftment of $\mathrm{GFP}^{+} \mathrm{BMSC}$ during wound healing}

To detect the plasticity of $\mathrm{GFP}^{+}$BMSCs, the healing wound tissue was measured after 28 and 35 days by TPF-SHG. Incredibly, $\mathrm{GFP}^{+}$BMSCs could be detected up to 35 days in the CS-N and CS-C group (Fig. 3a). To quantify the number of surviving cells, we extracted DNA from skin that had been repaired for 0,28 , and 35 days. In Fig. 1b, lanes 1, 2, and 3 represent the control group, CS-N group, and CS-C group, respectively, at 0 days; lanes 4,5 , and 6 represent the three groups at 28 days, and lanes 7, 8, and 9 represent the three groups at 35 days. At 42 days, BMSCs were hardly detected in all groups (data not shown). The results showed that GFP DNA in the CS-C group was increased 1.17-fold compared to the CS-N group at 0 days post-operation. However, after 28 days and 35 days of engraftment, the GFP DNA was 1.34 -fold and 1.53-fold increased, respectively, in the CS-C group compared to the CS-N group. Furthermore, the ratios of $\mathrm{GFP}^{+}$BMSC content at 28 days post-operation and 35 days post-operation compared with 0 days post-operation were 0.269 and 0.203 in the CS-C group and 0.219 and 0.143 in the CS-N group, respectively (Fig. 3d), which meant that there was a lower decreasing rate in the content of BMSCs in CS-C than that in CS-N. At 0, 28, and 35 days, the target bands of 


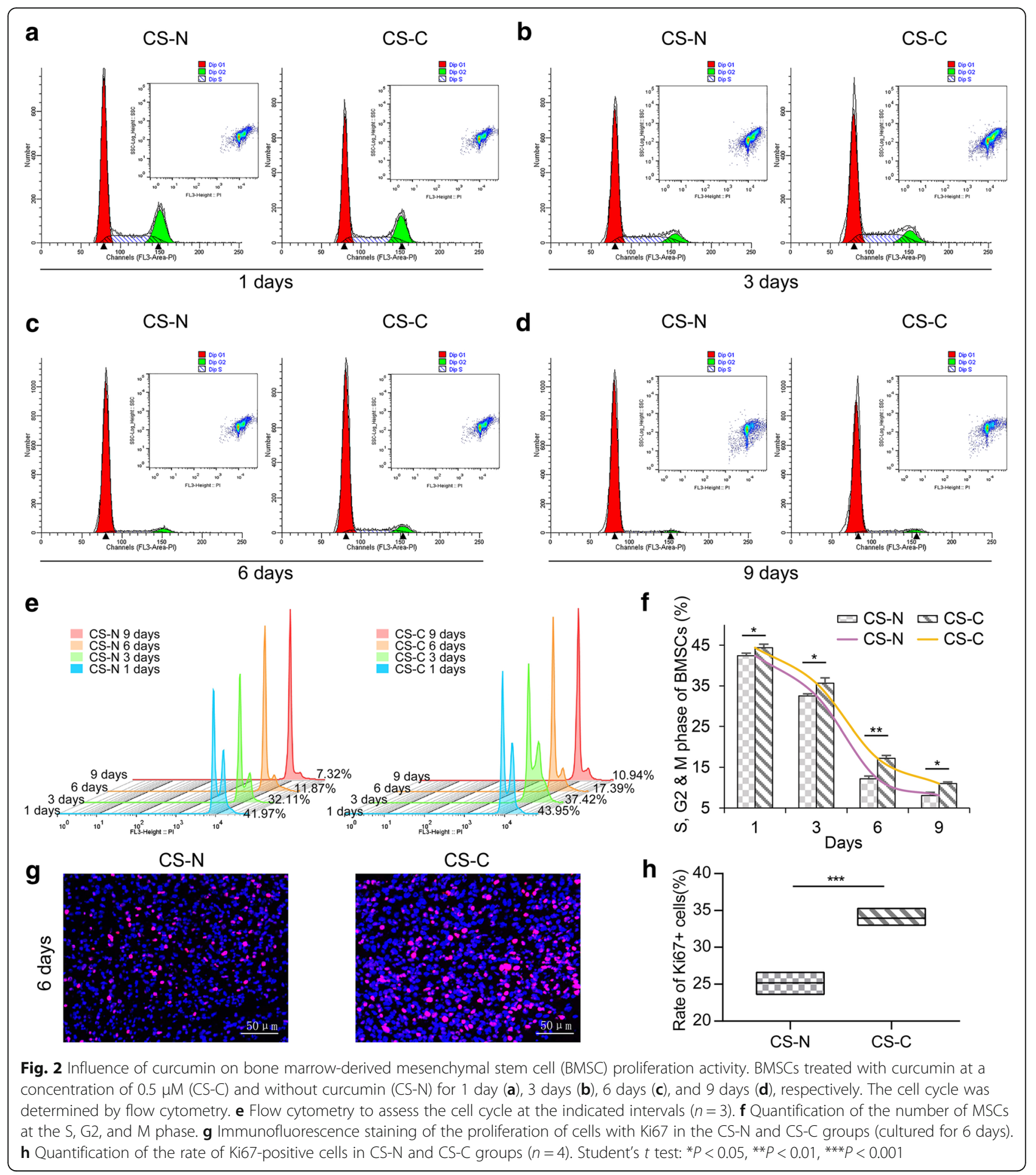

electrophoresis were excised for sequence alignment in both the forward and reverse directions. The product sequence was approximately $135 \mathrm{bp}$. The matching rate of the two sequences was very high (Fig. 3e). Overall, GFP ${ }^{+}$ BMSCs in the CS-C group showed improved engraftment and survival before 6 weeks than did those in the CS-N group.
Effect of curcumin on ECM secreted by the BMSC sheets BMSC sheets use the ECM secreted during the culture period as an endogenous scaffold, which is important for wound healing. The results of immunofluorescence showed that the secretion of types I and III collagen was increased in cell sheets cultured with curcumin (Fig. 4a, b). The growth of type III collagen in the CS-C group was 


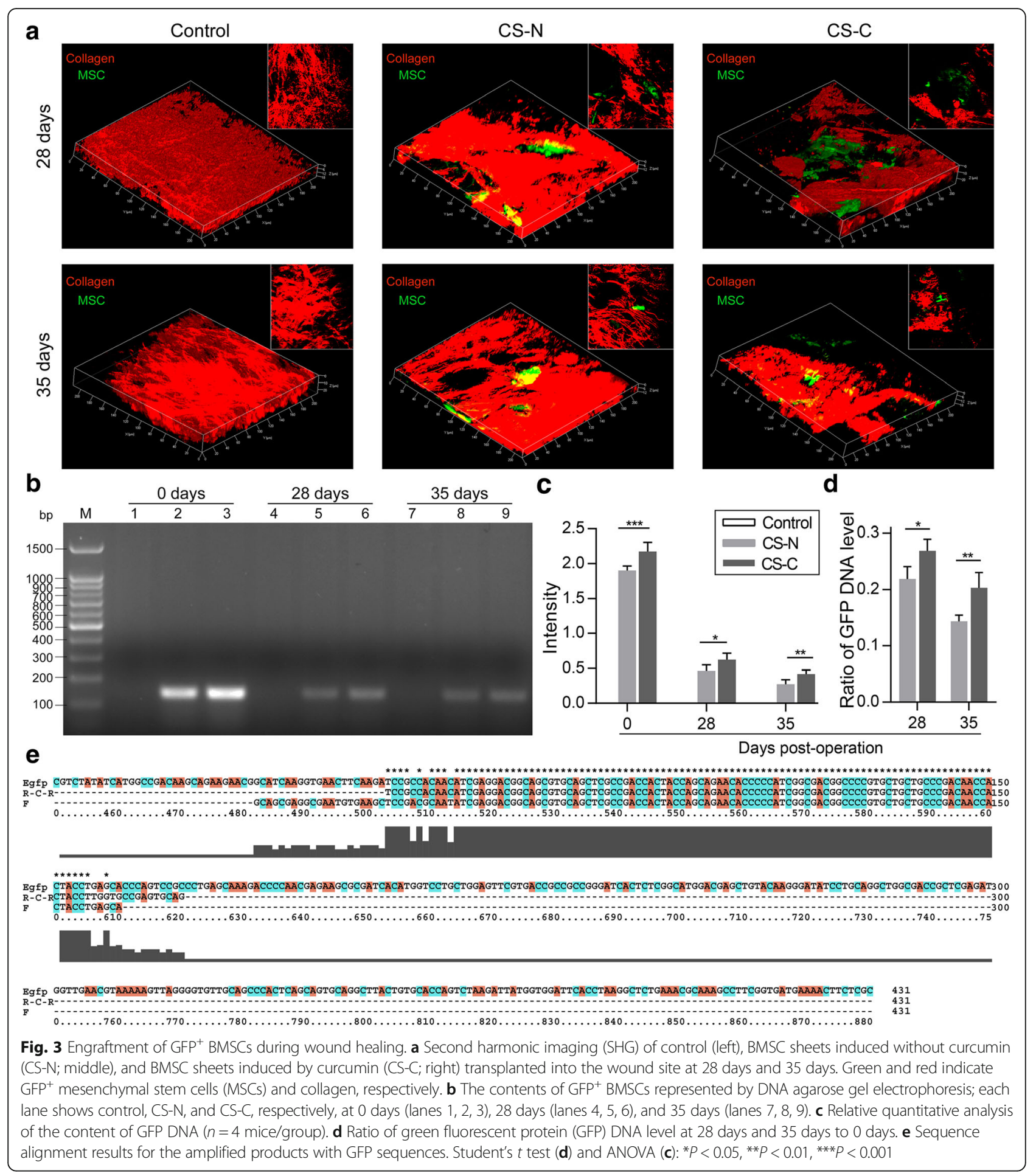

almost double that in the CS-N group (Fig. 4a-c). ECMrelated genes, including collagen type I, collagen type III, and fibronectin (FN), were determined by RT-PCR. The PCR results were consistent with the results of immunofluorescence. A higher expression of genes, including coll $\alpha 1$, col3 $\alpha 1$, and $F$ n, was detected in the CS-C group compared with the CS-N group and control group (BMSCs cultured in a culture bottle for 2 days) (Fig. 4d). To explore the ultrastructure of this endogenous scaffold, we compared the two scaffolds using an SEM. The cell sheets cultured with curcumin clearly had a more complete and thicker collagen structure (Fig. 4e, f). 


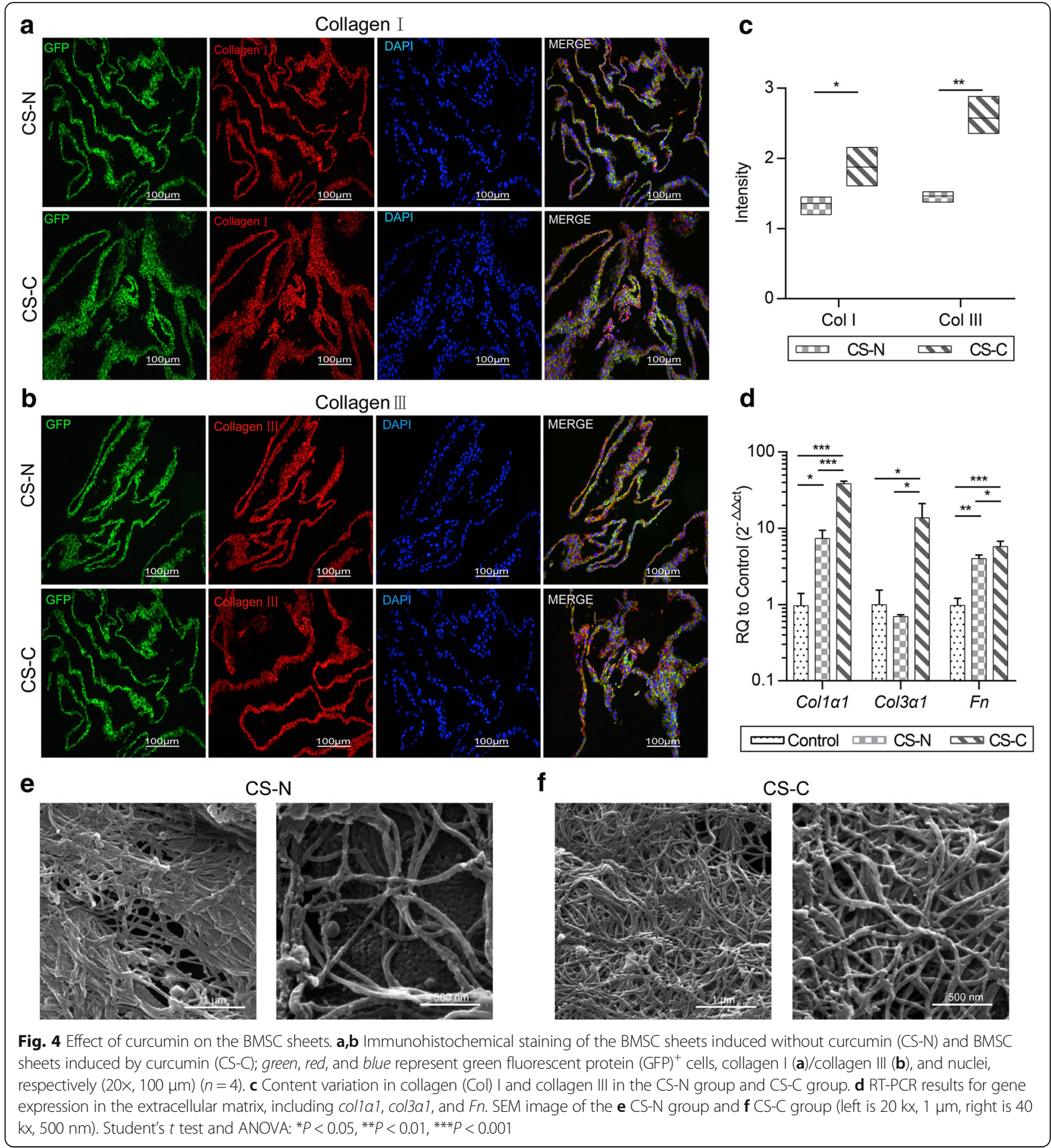

\section{CS-C recruits macrophage $(\mathrm{M})$ and $\mathrm{T}$ cells in early repair} stages

To explore the effects of CS-C on the immune response, we examined the immune environment around the wound site. First, we found that the gene expression of SDF1 in the curcumin treatment group was much higher than that in the no curcumin treatment group during the process of cell sheet culture (Fig. 5b). Also, this effect lasted until the sheet was transplanted into the wound at 7 days post-operation; the immunofluorescence images accompanying the results of PCR demonstrate this (Fig. 5a, c, f). SDF1 is a molecule that possesses potent chemotactic activity for leukocytes to participate in the inflammatory response on wound healing. Indeed, in our study, CD $45^{+}$leukocytes infiltration varied greatly between groups at 7 days post-operation. $\mathrm{CD} 45^{+}$leukocyte infiltration in the CS-C group was twice that in the control group and 1.5 times that in the 


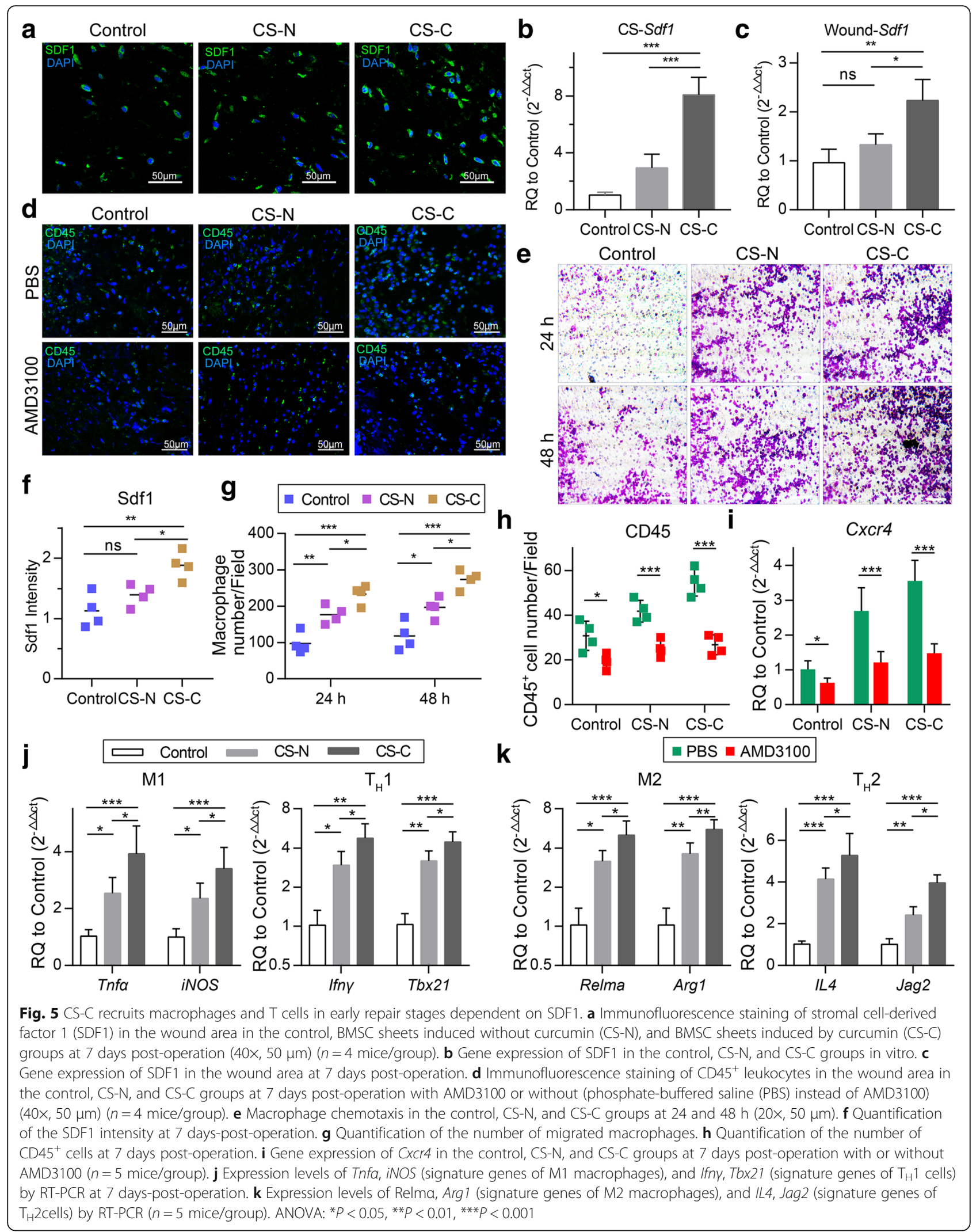


CS-N group (Fig. 5d), in favor of the detection and removal of germs. To further confirm whether CS-C had a recruitment effect on leukocytes, we selected macrophages to conduct in vitro migration experiments. The results showed that after 24 and $48 \mathrm{~h}$ CS-C did have a recruitment effect on macrophages, and more macrophages were recruited over time (Fig. 5e, g). To study whether SDF1 was the dominant factor inducing the leukocyte recruitment, we used AMD3100 to verify the role of SDF1. AMD3100 is the antagonist of CXCR4, a receptor specific for SDF1. The results showed that the gene expression of CXCR4 was significantly reduced with AMD3100 (Fig. 5i). CD45 ${ }^{+}$leukocyte infiltration also demonstrated a large reduction with the use of AMD3100 at 7 days post-operation (Fig. 5d, h), suggesting a direct role for SDF1 in recruiting leukocytes. As reported above, macrophages have two different types of function: pro-inflammation M1 and tissue-repairing M2, which correspond to $\mathrm{T}_{\mathrm{H}} 1$ and $\mathrm{T}_{\mathrm{H}} 2$ cells. In the PCR experiment in vivo, the expression of signature genes of M1 macrophages (Tnfo, iNOS), M2 macrophages (Relmo, Arg1), $\mathrm{T}_{\mathrm{H}} 1$ cells (Ifny, Tbx21), and $\mathrm{T}_{\mathrm{H}} 2$ cells (IL4, Jag2) (Jag2 encodes the Notch ligand Jagged2, which helps $\mathrm{T}_{\mathrm{H}} 2$ differentiation) was significantly increased in the CS-C group compared with the control group and $\mathrm{CS}-\mathrm{N}$ group (Fig. 5j, k). Thus, CS-C enhanced the immune response when first transplanted into the wound.

\section{CS-C accelerates type I immune reaction regression and M2 macrophage polarization}

After 7 days post-operation, there were tremendous changes in the immune environment. The number of pro-inflammatory M1 macrophages and associated $\mathrm{T}_{\mathrm{H}} 1$ cells declined dramatically. The results of immunofluorescence showed that the number of M1 macrophages and $\mathrm{T}_{\mathrm{H}} 1$ cells as characterized by CD11c and IFNY in the CS-C group was much lower than that in the CS-N and control groups at 14, 21, and 28 days post-operation (Fig. 6a-d). Furthermore, there was a significant decrease in Tnfo and iNOS (signature genes of M1 macrophages) and Ifny and Tbx21 (signature genes of $\mathrm{T}_{\mathrm{H}}$ 1cells) mRNA between the CS-C group and the CS$\mathrm{N}$ and control groups at 14 and 21 days post-operation, but no significant difference at 28 days post-operation (Fig. $6 \mathrm{e}-\mathrm{g}$ ). The above results show that the CS-C group has a shorter type I immune response and can accelerate type I immune reaction regression. The general trend is that the M1 macrophages, $\mathrm{T}_{\mathrm{H}} 1$ cells, increase dramatically by 7 days, decline after 14 days, and then moderate by 28 days (Fig. $6 \mathrm{~h}, \mathrm{i}$ ).

On the other hand, an increasing number of M2 macrophages were activated. The mRNA level of the M2 macrophages, marked by Relma and Arg1, tended to be increased in the CS-C group at 14 days post-operation and there was no significant difference between the three groups at 21 or 28 days post-operation (Fig. $7 \mathrm{f}-\mathrm{g}$ ). The results of Relma $\alpha^{+}$M2 macrophage immunofluorescence also confirmed this (Fig. 7a, b). More M2 macrophages in the CS-C group were polarized during 7 to 14 days post-operation compared to the situation at 7 days post-operation (Fig. 7e). Furthermore, immunosuppressive cytokines secreted by BMSCs, such as TGF $\beta$ and IL1RN, were shown to promote the polarization of M2 macrophages. The mRNA levels of TgfB, IL1RN and $\operatorname{Tgf} \beta^{+}$, IL1RN ${ }^{+}$immunofluorescence increased in the CS-C group at 14 days post-operation compared to the CS-N and control groups (Fig. 7c, d). Therefore, the CS$\mathrm{C}$ group demonstrated the capability of recruiting more tissue-repairing immune cells to promote wound regeneration in the later stages of wound repair. At the same time, it effectively prevented chronic inflammation.

\section{CS-C promotes skin reconstruction}

Mice were euthanized at 3, 7, 14, 21, and 28 days postoperation to evaluate whether the wound was repaired better after CS-C treatment. Skin samples were used to observe what changes had occurred in the wound tissue during the wound healing process. First, we observed that the wound was fully closed after about 14 days with a small and obscure scar found after 28 days in the CS$\mathrm{C}$ group. However, in the control and CS-N groups, the wound was only almost closed at 21 days post-operation, with a scab covering. Furthermore, a clear, over fibrotic scar could be seen in the later stages of repair of the CS$\mathrm{N}$ and control groups (Fig. 8b, c). To further analyze the details of the wound healing, we stained $3,7,14,21$, and 28 days post-operation wound samples with $\mathrm{H} \& \mathrm{E}$. The CS-C group began to form new epidermis at 7 days post-operation, but neoepidermis was only noted at 14 days post-operation for the control and CS-N groups. At 28 days post-operation, stratified epidermis structures, including hair follicles and sweat glands, could be observed in the CS-C group. On the other hand, the epidermal thickness of the CS-C group at 28 days postoperation was more like that of normal skin tissue than the control or CS-N groups (Fig. 8a). Masson trichrome staining indicated that the CS-C group had mature bundles of collagen deposition in a certain direction and more dense blood vessels, more like the normal group, while the control and CS-N groups has disorganized collagen (Fig. 8d).

\section{Discussion}

BMSC sheet technology has been studied for applications over recent years, and one of its major advantages is that it could avoid the damage of enzyme digestion to preserve better activity of the BMSCs. BMSCs have a beneficial effect on cutaneous wound healing and skin 

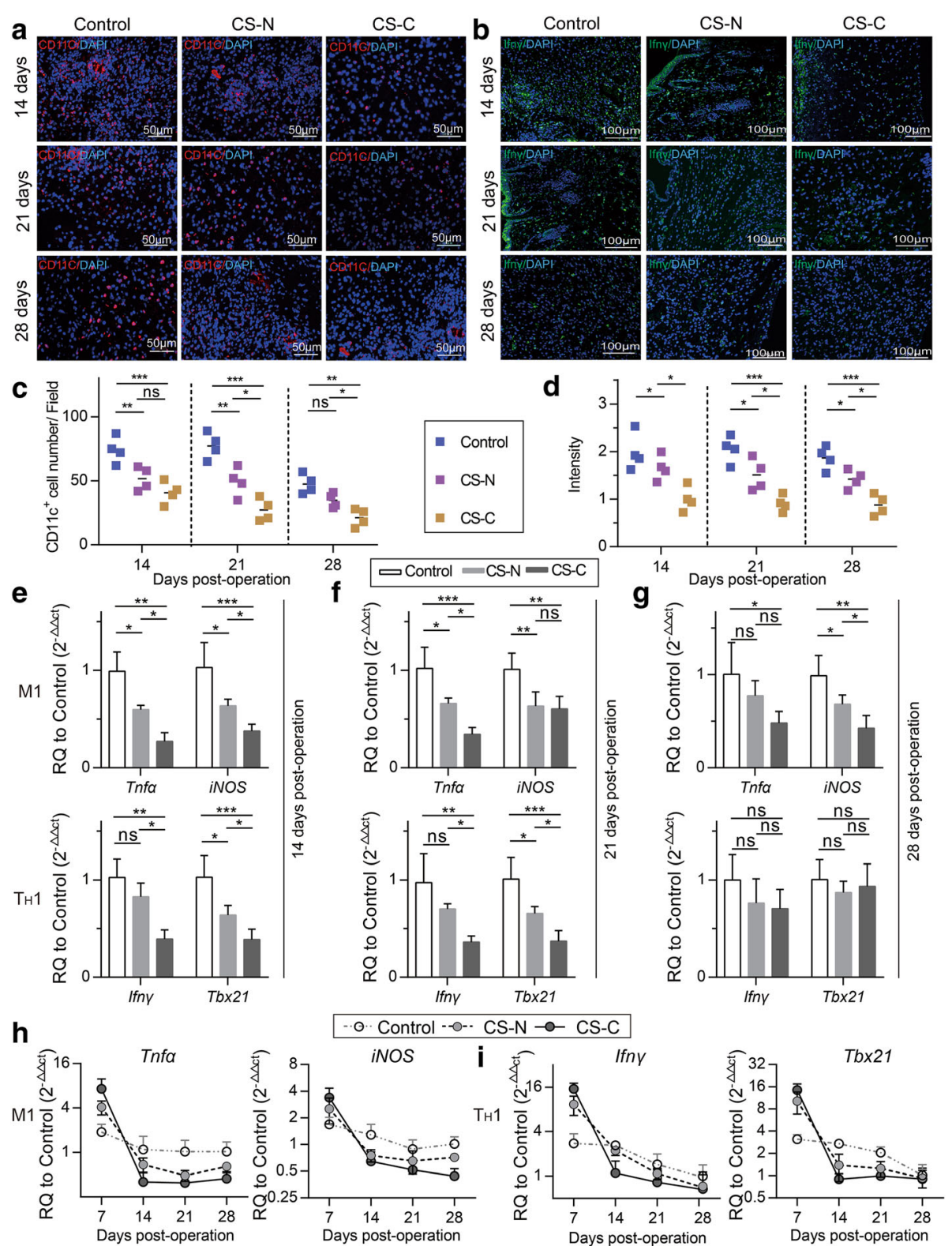

Fig. 6 CS-C accelerated type I immune reaction regression. a Immunofluorescence staining of CD11 $\mathrm{C}^{+} \mathrm{M} 1$ macrophages in the control, BMSC sheets induced without curcumin (CS-N), and BMSC sheets induced by curcumin (CS-C) groups at 14, 21, and 28 days after treatment. Red and blue represent CD11 $\mathrm{C}^{+} \mathrm{M} 1$ macrophages and nuclei, respectively $(20 \times, 50 \mu \mathrm{m})(n=4$ mice/group). $\mathbf{b}$ Immunofluorescence staining of interferon (IFN)y at 14, 21, and 28 days. Green and blue represent T helper $1\left(T_{H} 1\right)$ cells and nuclei, respectively (bar $\left.=100 \mu \mathrm{m}\right)(n=4$ mice/group). Quantification of c the number of M1 macrophages and $\mathbf{d} \mathrm{T}_{\mathrm{H}} 1$ cells, respectively. Expression levels of Tnfa and iNOS (signature genes of M1 macrophages) and Ifny and Tbx21 (signature genes of $\mathrm{T}_{\mathrm{H}} 1$ cells) by RT-PCR at 14 (e), 21 (f), and 28 days (g) after transplantation with saline, CS-N, and CS-C ( $n=5$ mice/group). M1 (h) and $\mathrm{T}_{\mathrm{H}} 1$ (i) signature gene expression during the whole experimental period for the control, CS-N, and CS-C groups. ANOVA: ${ }^{*} P<0.05,{ }^{*} P<0.01$, ${ }^{* * *} P<0.001$. ns not significant

regeneration in many different ways, including differentiation, endocrine, and paracrine effects, as well as the most important immune response modulatory capability [31, 32]. BMSCs secrete diverse cytokines and growth factors that have anti-fibrotic properties to minimize the formation of scar tissue, such as hepatocyte growth factor (HGF), which has been shown to suppress overexpression of collagens and increase MMP-1 and MMP-13 expression in fibroblasts [33, 34]. Moreover, BMSCs communicate with the inflammatory microenvironment to initiate their immunomodulatory functions. When stimulated by IFN $\gamma$, TNF $\alpha$, or IL- $1 \alpha$, BMSCs exhibit immunosuppression, inhibiting T-cell proliferation and differentiation into $\mathrm{T}_{\mathrm{H}} 1$ cells [35]. Other studies 

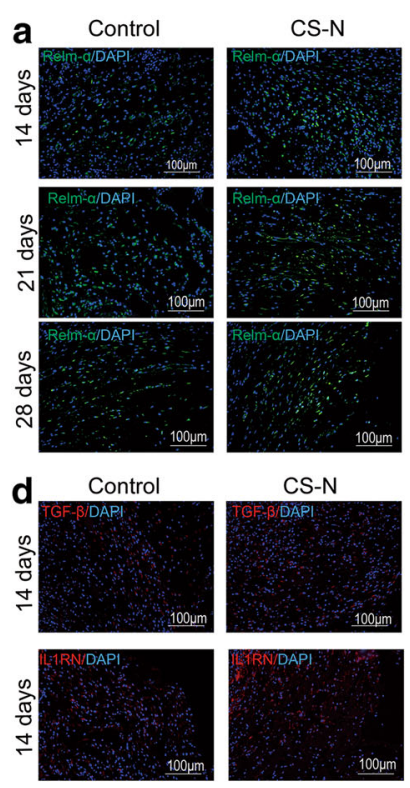

CS-N
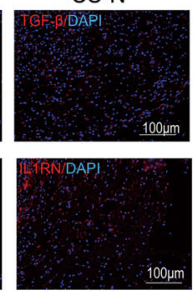

f

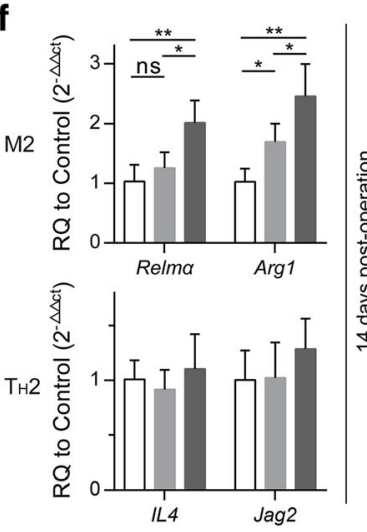

CS-C

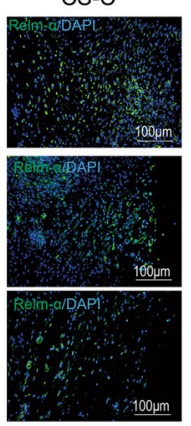

CS-C

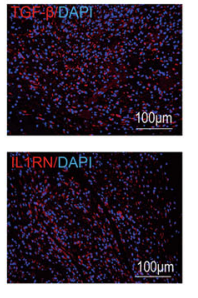

g

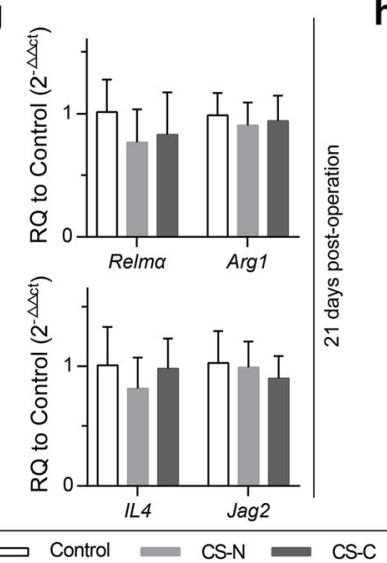

C
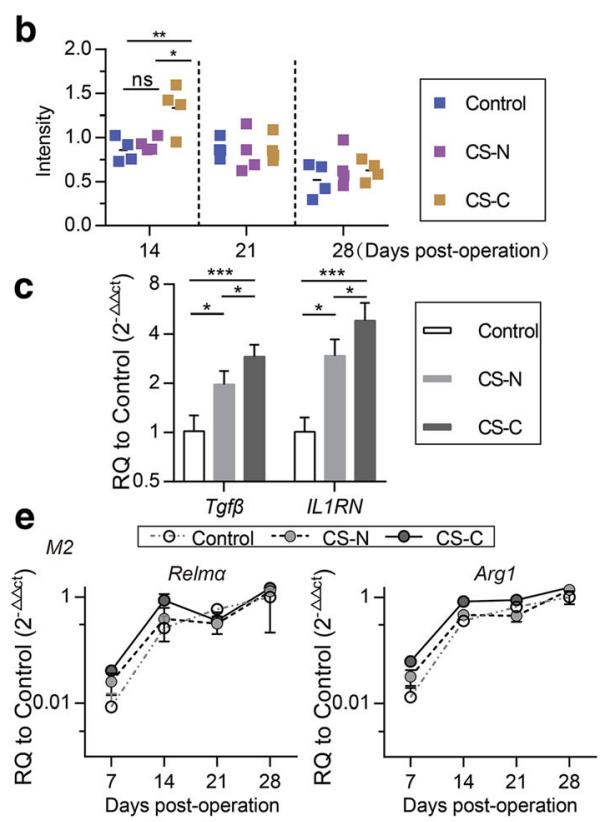

h

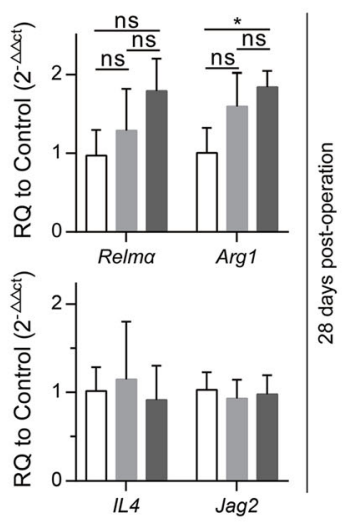

Fig. 7 CS-C accelerated M2 macrophage polarization. a Immunofluorescence staining of Relma in the control, BMSC sheets induced without curcumin (CS-N), and BMSC sheets induced by curcumin (CS-C) groups at 14, 21, and 28 days after treatment. Red and blue represent Relma and nuclei, respectively (20x, $100 \mu \mathrm{m})(n=4$ mice/group). b Quantification of the Relma intensity. c Expression levels of Tgf $\beta$ and ILIRN by RT-PCR at 14 days post-operation ( $n=5$ mice/group). $\mathbf{d}$ Immunofluorescence staining of $\operatorname{Tgf~}^{+}$(top panels) and IL1RN ${ }^{+}$(bottom panels) cells in the three groups at 14 days post-operation. Red represents Tgf $\beta$ and IL1RN, and blue represents nuclei $(20 \times, 100 \mu \mathrm{m})(n=4$ mice/group). e M2 signature gene expression during the whole experimental period for the control, CS-N, and CS-C groups. Expression levels of Relma and Arg1 (signature genes of M2 macrophages) and IL4 and Jag2 (signature genes of $\mathrm{T}_{\mathrm{H}} 2$ cells) by RT-PCR at 14 (f), 21 (g), and 28 days (h) after transplantation with saline, CS-N, and CS-C ( $n=5$ mice/group). ANOVA: ${ }^{*} P<0.05,{ }^{* *} P<0.01$, ${ }^{* *} P<0.001$. ns not significant

show that BMSCs are effective for converting macrophages from the pro-inflammatory M1 type to the antiinflammatory M2 type [14, 15].

With this mind, strategies to mediate BMSCs to produce a desirable BMSC sheet with further enhancement of the proliferation of BMSCs, and to guide the expression of suitable wound repair factors thus inducing a proper immune response to promote wound healing, are key points of this study. It is wise to regulate BMSCs, which are beneficial for skin regeneration, via epigenetic modifications. Some suitable small molecules that can be easily synthesized, preserved, and standardized are the first choice [36]. Studies have confirmed that the functional ingredients in certain Chinese herbs can influence cell behavior [37] and further improve BMSC sheets to promote bone formation in metaphyseal defects [38]. Curcumin is a natural polyphenolic substance extracted from zingiberaceae roots, and has been shown to have anti-inflammatory and anti-fibrosis effects in cutaneous wound healing. Therefore, in this study, we initiated a modified epigenetic strategy using curcumin to rejuvenate BMSCs and to improve the functional BMSC 


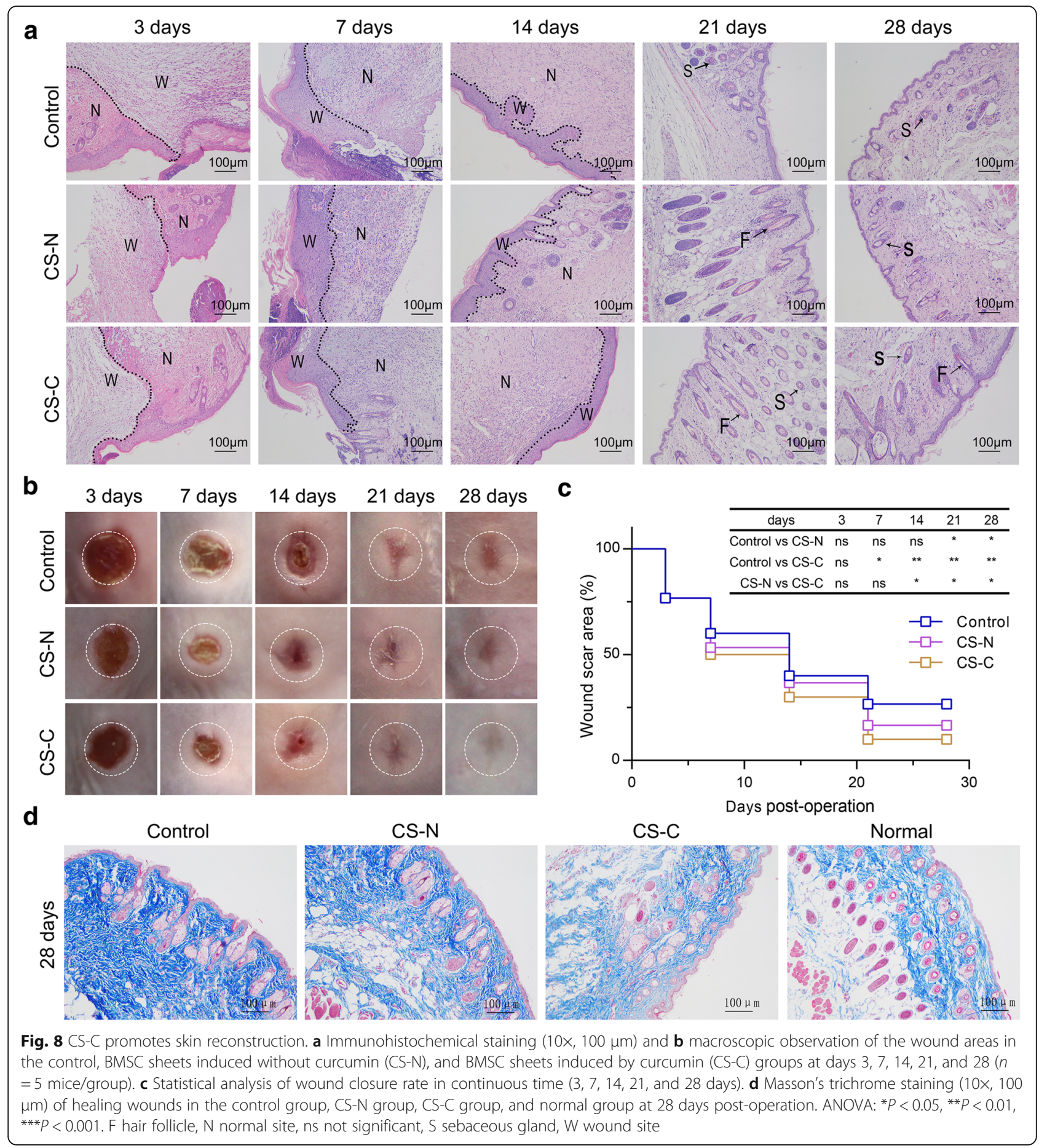

sheet to promote cutaneous wound healing. Modified epigenetics refers to those variations of epigenetic components that result in changes in specific chromatin architecture that activate or deactivate expression of the regulatory genes, and finally impose influence on cell fate determination but without changing DNA sequences [39]. In our study, after being stimulated by curcumin, BMSCs transcribed more SDF1 to recruit immune cells at 7 days post-operation, and more immunosuppressive factors such as TGF $\beta$ and IL1RN were secreted by BMSCs at 14 days post-operation to suppress the type I immune response and promote M2 polarization; therefore, the application of curcumin was thought to be a modified epigenetic strategy for BMSCs.

The therapeutically relevant delivery and survival rate of BMSCs grafted to the wound area are extremely 
important parameters for wound regeneration, and determines for how many and how long the BMSCs exert their pro-healing effects [40]. However, in most studies, such as in the system of BMSC administration alone, the delivered number of BMSCs for engraftment is poor or the engrafted BMSCs tend to be short-lived in the wound area, surviving around 14 days [41]. However, after implantation of the curcumin-mediated BMSC sheet, both TPF/SHG imaging and DNA amplification demonstrated that $\mathrm{GFP}^{+}$BMSCs could still be detected up to 35 days post-operation. Furthermore, BMSCs in the CS-C group showed better engraftment than those in the CS-N group. More BMSCs survived and, of these, more BMSCs were in the cell replication period of $\mathrm{S}$, G2, or M phase after treatment with curcumin, as shown in Fig. 2f, suggesting that curcumin significantly enhanced the proliferation of BMSCs. Previous research by ourselves and others have shown that BMSCs affect other cells primarily through paracrine effects to participate in the process of tissue repair and immune regulation [30]. Greater numbers and longer survival rates ensured that the BMSCs secreted more cytokines to promote wound healing by enhancing the immunomodulatory ability of the above-described BMSCs. Curcumin amplified the delivery and efficacy of BMSCs and thus could reinforce its pro-healing functions by promoting vascular endothelial cell proliferation to increase angiogenesis, regulating macrophage and T-cell functions to avoid chronic inflammation, as well as producing antifibrotic factors to reduce scar formation [42, 43]. Moreover, secretion of SDF1 by the BMSC sheet was greatly increased after curcumin treatment as shown in Fig. 5b. In addition to being able to recruit large number of leukocytes, SDF1 was sufficient to enhance endogenous BMSC recruitment to the injury site [44]. In our study, endogenous BMSCs may have also been recruited to promote wound healing; however, this possibility requires further research.

It is clear that immune cells are important regulators of regeneration, not only because of their ability to prevent infection and clear necrotic tissue but also because of their powerful influence in shaping the microenvironment during repair and development. The persistent presence of pro-inflammatory factors such as TNF $\alpha$ and IFN $\gamma$, among others, secreted by $\mathrm{T}_{\mathrm{H}} 1$ and $\mathrm{M} 1$ macrophages may result in extensive secondary damage and chronic inflammation, and can compromise the function of tissues [45]. However, there is also evidence to indicate that the existence of IFN $\gamma$, TNF $\alpha$, and IL-1 $\beta$ activate the immunomodulatory phenotype of BMSCs [46]. In our study, the abundance of SDF1 produced by CS-C led to a mass migration of leukocytes; among these, $\mathrm{T}_{\mathrm{H}} 1$ cells and associated pro-inflammatory M1 macrophages demonstrated an increase at 7 days post-operation. The immunosuppressive phenotype of BMSCs might then be activated by the secreted pro-inflammatory factors $(\mathrm{IFN} \gamma, \mathrm{TNF} \alpha)$ via those leukocytes and release several factors relevant to the immunosuppressive function, including TGF $\beta$ and IL1RN [47]. It is worth noting that IL1RN and TGF $\beta$ have been shown to promote the differentiation of M2 macrophages [48, 49]. To confirm this, increased expression of TGF $\beta$ and IL1RN in the CS-C group at 14 days post-operation was seen in our study (Fig. $7 \mathrm{~d}$ ). The number of $\mathrm{T}_{\mathrm{H}} 1$ cells and $\mathrm{M} 1$ macrophages was subsequently found to be sharply decreased in the CS-C group at 14 days post-operation (Fig. 6h, i), suggesting a shorter type I immune response here, which is thought to be critical for improving the survival rate of BMSCs and avoiding chronic inflammation $[4,50]$. Also, recent studies have suggested that the type II immune response can improve inflammation-mediated tissue damage and induce repair in missing tissue [51], while a persistent presence of excessive M2 macrophages or $\mathrm{T}_{\mathrm{H}} 2$ cell activities could unavoidably cause fibrosis [52-54]. In the CS-C group in our study, during the early stage of repair, there was a strong trend towards $\mathrm{T}_{\mathrm{H}} 2$ activation (0-7 days) and M2 polarization (7-14 days) and, fortunately, at the later stage (after 14 days), the number of M2 macrophages fell (Fig. 7e). This is a favorable immune response which is generally believed to produce anti-inflammatory effects and can improve wound repair [55]. The Masson's trichrome staining in Fig. 8d showed that the rebuilt tissue collagen in the CS$\mathrm{C}$ group was more like normal tissue in content and organization than that in the CS-N and control groups. In addition, M2 macrophages, if in a substantial number, have been shown to have an inhibitory function on the activation of $\mathrm{M} 1$ macrophages and $\mathrm{T}_{\mathrm{H}} 1$ cells [56]. The existence of a large number of M2 macrophages during days 7-14 of repair may explain the decline in $\mathrm{T}_{\mathrm{H}} 1$ cells and M1 macrophages in the later period (after 14 days) in our study, as shown in Figs. 6h, i, and 7e. The curcumin-treated cell sheet (CS-C), therefore, has been shown to have a powerful ability to create a proregenerative microenvironment at the site of implantation.

ECM provides cells with a dynamic niche and influences the cell immune microenvironment as a scaffold. Biological scaffolds sourced from ECM are thought to be beneficial to tissue repair $[57,58]$ and have been successfully used for tissue reconstruction in skin, skeletal muscle, the esophagus, and the lower urinary tract [59-62]. Recent research has demonstrated that ECM scaffolds possess the ability to alter the default wound healing response from pro-inflammatory towards proregenerative [15]. We noticed in our study that curcumin promoted high secretion levels of Fn, which mediates cellmatrix adhesion and enhances the contents and the ratio of collagen III and I; these constitute the main framework 
of the endogenous ECM in the BMSC sheet. Therefore, we are aware that curcumin alters the features of endogenous ECM in the BMSC sheet. Amino acids are believed to be in charge of the polarization of M2 macrophages in the immune response of wound healing. It is proposed that amino acids play a role via amino acidsensing pathways (Lamtor1, v-ATPase, and mTORC1) where the amino acid is engulfed by macrophages and digested by their abundantly developed lysosomes. Sufficient amino acids and IL-4 integrate to the lysosomal adaptor protein Lamtor1, v-ATPase, and mTORC1, leading to production of 25-hydroxycholesterol and subsequent activation of liver $\mathrm{X}$ receptor (LXR), which ultimately results in polarization of M2 macrophages [7]. In our study, collagen in the endogenous ECM scaffold could be a possible rich source of amino acids, and the enhancement in collagen content in the ECM in the CS-C group could be the reason for better M2 macrophage polarization association. Also, it is well known that in fetal skin there is a process of scarless wound healing. This wound healing response of fetal skin is believed to be intrinsic to the fetal skin ECM rather than the fetal

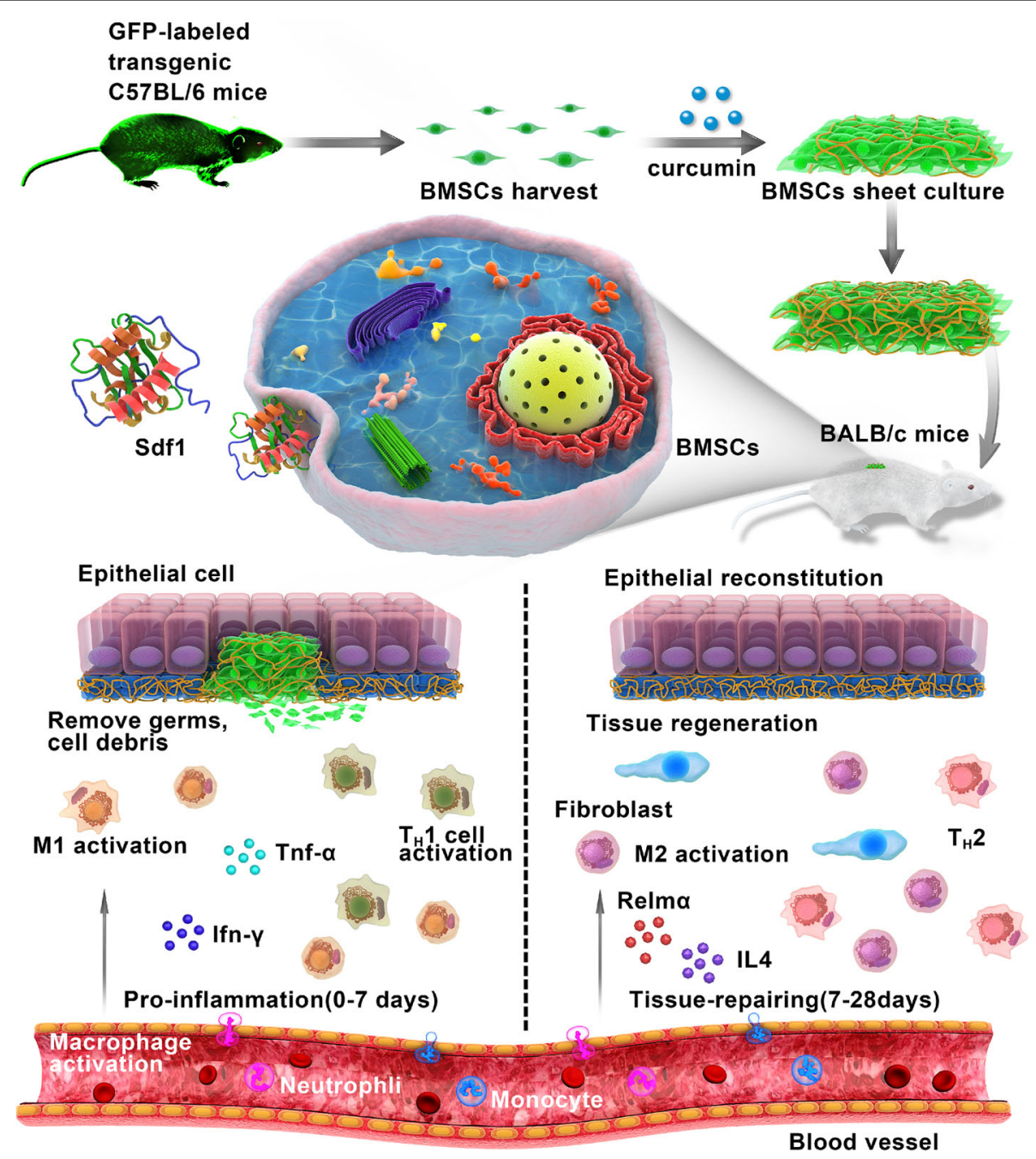

Fig. 9 The CS-C-based immunomodulatory process in wound healing. Green fluorescent protein (GFP) ${ }^{+}$bone marrow-derived stem cells (BMSCs) were harvested from transgenic C57BL/6 mice. BMSC sheets were prepared by culturing $1.5 \times 10^{5}$ third passage cells on culture dishes for 12 days. The BMSC sheets were then transplanted into the skin wounds of the recipient mice. Once CS-C is applied to the wound site, it induces the secretion of various chemokines. Stromal cell-derived factor 1 (Sdf1) increases significantly, recruiting more leukocytes, such as macrophages (M) and T helper $\left(T_{H}\right)$ cells, to the wound area. Abundant type I immune cells of $M 1$ macrophages and $T_{H} 1$ cells are activated at approximately 7 days of repair in the pro-inflammatory stage. The temporary pro-inflammatory response leads to the rapid removal of foreign pathogens. After 7 days post-operation, the typical type I immune response, the number of $\mathrm{M} 1$ macrophages and $\mathrm{T}_{H} 1$ cells near the wound are greatly reduced; instead, there is an increase in type II immune response, as reflected in the number of anti-inflammatory M2 macrophages. Timely suppression of the type I immune reaction allows rapid tissue rebuilding, and the increase in type II anti-inflammatory M2 macrophages in the following stage is beneficial for tissue repairing. Through the transplantation of CS-C, rapid and effective skin wound healing occurs. Ifn interferon, IL interleukin, Tnf tumor necrosis factor 
environment [63]. Unlike adult skin ECM which is primarily composed of collagen I, fetal ECM has high ratio of collagen III/I [64]. Our endogenous ECM scaffold induced by CS-C possesses properties that are more like that of fetal skin, with a high ratio of collagen III/I (Fig. 4d), and this may be helpful in reducing the effect of scar tissue in adult full-thickness cutaneous wound healing.

To summarize, we demonstrated that the Traditional Chinese Medicine curcumin is an effective regulator for altering the characteristics of the BMSC sheet. It not only allows BMSCs to present better proliferating activity and better engraftment, but it also produces a more suitable endogenously secreted ECM scaffold. Most importantly, this new type of biomaterial establishes an immune response that is favorable for adult cutaneous wound healing, which promotes repair of the cutaneous wound quickly and with improved quality. Figure 9 diagrammatically shows the model of CS-C and the CS-Cbased immunomodulatory process in wound healing.

\section{Conclusion}

This study introduces a promising new biomaterial (CSC), which is a TCM curcumin-regulated BMSC sheet. Curcumin improved the characteristics of the BMSC sheet, including BMSC activity, behavior, and ECM components. When it is applied for full-thickness cutaneous wound healing, CS-C possesses properties of immunoplasticity, which plays a vital role in immunoregulation during wound repair and promotes tissue reconstruction. In addition, the CS-C group had better engraftment since curcumin can enhance the delivery and efficacy of BMSCs to reinforce its pro-healing functions. These results demonstrate that the specific BMSC sheet induced with curcumin could be a promising biomaterial for adult full-thickness cutaneous wound healing, providing a new perspective for the future treatment of skin wound repair.

\footnotetext{
Abbreviations

BMSC: Bone marrow-derived mesenchymal stem cell; CS-C: BMSC sheets induced by curcumin; CS-N: BMSC sheets induced without curcumin; ECM: Extracellular matrix; FN: Fibronectin; GFP: Green fluorescent protein; H\&E: Hematoxylin and eosin; IFN: Interferon; IGF: Insulin-like growth factor; IL: Interleukin; IL1RN: Interleukin-1 receptor antagonist; PBS: Phosphatebuffered saline; PDGF: Platelet-derived growth factor; RT-PCR: Real-time polymerase chain reaction; SDF1: Stromal cell-derived factor 1; SEM: Scanning electron microscopy; SHG: Second-harmonic generation; TCM: Traditional Chinese Medicine; TGF: Transforming growth factor; TNF: Tumor necrosis factor; TPF: Two-photon fluorescence; VEGF: Vascular endothelial growth factor
}

\section{Acknowledgments}

The authors acknowledge Ning Wang and Maosheng Chen for their suggestions on experimental operation.

\section{Funding}

This work was supported by the National Natural Science Foundation of China (no. 81671729) and (no. 81171379).

Availability of data and materials Not applicable.

\section{Authors' contributions}

ZY and XD designed the study, developed the CS-C, and revised the manuscript $\mathrm{CH}$ was responsible for in vivo experimental tissue harvest. JH provided the main experimental instruments. JC and HL performed the statistical analyses. All authors read and approved the final manuscript.

\section{Ethics approval}

All experimental protocols were approved by the Ethical Committee for Animal Experiments of South China Normal University. All animal experiments conducted in this research were performed in accordance with the guidelines of South China Normal University Intramural Animal Use and Care Committee and met the NIH guidelines for the care and use of laboratory animals.

\section{Consent for publication}

All authors have read and approved the manuscript for publication.

\section{Competing interests}

The authors declare that they have no competing interests.

\section{Publisher's Note}

Springer Nature remains neutral with regard to jurisdictional claims in published maps and institutional affiliations.

\section{Author details}

'MOE Key Laboratory of Laser Life Science, College of Biophotonics, South China Normal University, No. 55 Zhongshan Avenue West, Tianhe District, Guangzhou 510631, China. ${ }^{2}$ Tropical Medicine Institute, Guangzhou University of Chinese Medicine, Guangzhou, China.

Received: 24 October 2017 Revised: 13 December 2017 Accepted: 2 January 2018 Published online: 31 January 2018

\section{References}

1. Stadelmann WK, Digenis AG, Tobin GR. Physiology and healing dynamics of chronic cutaneous wounds. Am J Surg. 1998;176:26S-38S.

2. Falanga $V$. Wound healing and its impairment in the diabetic foot. Lancet. 2005;366:1736-43.

3. Wynn TA, Ramalingam TR. Mechanisms of fibrosis: therapeutic translation for fibrotic disease. Nat Med. 2012;18:1028-40.

4. Nagaraja S, Wallqvist A, Reifman J, Mitrophanov AY. Computational approach to characterize causative factors and molecular indicators of chronic wound inflammation. J Immunol. 2014;192:1824-34.

5. Duffield JS, Forbes SJ, Constandinou CM, Clay S, Partolina M, Vuthoori S, Wu $\mathrm{S}$, Lang $\mathrm{R}$, Iredale JP. Selective depletion of macrophages reveals distinct, opposing roles during liver injury and repair. J Clin Invest. 2005;115:56-65.

6. Stefater JR, Ren S, Lang RA, Duffield JS. Metchnikoff's policemen: macrophages in development, homeostasis and regeneration. Trends Mol Med. 2011;17:743-52.

7. Kimura T, Nada S, Takegahara N, Okuno T, Nojima S, Kang S, Ito D, Morimoto K, Hosokawa T, Hayama Y, et al. Polarization of M2 macrophages requires Lamtor that integrates cytokine and amino-acid signals. Nat Commun. 2016;7:13130.

8. Ishida Y, Gao JL, Murphy PM. Chemokine receptor CX3CR1 mediates skin wound healing by promoting macrophage and fibroblast accumulation and function. J Immunol. 2008;180:569-79.

9. Wynn TA, Vannella KM. Macrophages in tissue repair, regeneration, and fibrosis. Immunity. 2016;44:450-62.

10. Novak ML, Koh TJ. Macrophage phenotypes during tissue repair. J Leukoc Biol. 2013;93:875-81.

11. Kourembanas S. Expanding the pool of stem cell therapy for lung growth and repair. Circulation. 2014;129:2091-3.

12. Chou CL, Rivera AL, Williams V, Welter JF, Mansour JM, Drazba JA, Sakai T, Baskaran $\mathrm{H}$. Micrometer scale guidance of mesenchymal stem cells to form structurally oriented large-scale tissue engineered cartilage. Acta Biomater. 2017:60:210-19.

13. Caplan Al. Adult mesenchymal stem cells for tissue engineering versus regenerative medicine. J Cell Physiol. 2007;213:341-7.

14. Nemeth K, Leelahavanichkul A, Yuen PS, Mayer B, Parmelee A, Doi K, Robey PG, Leelahavanichkul K, Koller BH, Brown JM, et al. Bone marrow stromal cells attenuate sepsis via prostaglandin E(2)-dependent reprogramming of host macrophages to increase their interleukin-10 production. Nat Med. 2009;15:42-9. 
15. Abumaree MH, Al JM, Kalionis B, Jawdat D, Al KA, Abomaray FM, Fatani AS Chamley LW, Knawy BA. Human placental mesenchymal stem cells (pMSCs) play a role as immune suppressive cells by shifting macrophage differentiation from inflammatory M1 to anti-inflammatory M2 macrophages. Stem Cell Rev. 2013;9:620-41

16. Luz-Crawford P, Kurte M, Bravo-Alegria J, Contreras R, Nova-Lamperti $E_{\text {, }}$ Tejedor G, Noel D, Jorgensen C, Figueroa F, Djouad F, Carrion F. Mesenchymal stem cells generate a CD4 + CD25 + Foxp3+ regulatory T cell population during the differentiation process of Th1 and Th17 cells. Stem Cell Res Ther. 2013:4:65.

17. Yang J, Yamato M, Nishida K, Ohki T, Kanzaki M, Sekine H, Shimizu T, Okano T. Cell delivery in regenerative medicine: the cell sheet engineering approach. J Control Release. 2006;116:193-203.

18. Ishikawa I, Iwata T, Washio K, Okano T, Nagasawa T, Iwasaki K, Ando T. Cell sheet engineering and other novel cell-based approaches to periodontal regeneration. Periodontol. 2009;51:220-38.

19. Cerqueira MT, Pirraco RP, Martins AR, Santos TC, Reis RL, Marques AP. Cell sheet technology-driven re-epithelialization and neovascularization of skin wounds. Acta Biomater. 2014;10:3145-55.

20. Liu H, Zhou W, Ren N, Feng Z, Dong Y, Bai S, Jiao Y, Wang Z, Zhao Y. Cell sheets of co-cultured endothelial progenitor cells and mesenchymal stromal cells promote osseointegration in irradiated rat bone. Sci Rep. 2017;7:3038

21. Zhang H, Liu S, Zhu B, Xu Q, Ding Y, Jin Y. Composite cell sheet for periodontal regeneration: crosstalk between different types of MSCs in cell sheet facilitates complex periodontal-like tissue regeneration. Stem Cell Res Ther. 2016;7:168

22. Nagase K, Nagumo Y, Kim M, Kim HJ, Kyung HW, Chung HJ, Sekine H, Shimizu T, Kanazawa H, Okano T, et al. Local release of VEGF using fiber mats enables effective transplantation of layered cardiomyocyte sheets. Macromol Biosci. 2017;17:1700073.

23. Discher DE, Mooney DJ, Zandstra PW. Growth factors, matrices, and forces combine and control stem cells. Science. 2009;324:1673-7.

24. Liu L, Han L, Wong DY, Yue PY, Ha WY, Hu YH, Wang PX, Wong RN. Effects of Si-Jun-Zi decoction polysaccharides on cell migration and gene expression in wounded rat intestinal epithelial cells. Br J Nutr. 2005;93:21-9.

25. Luo X, Huang P, Yuan B, Liu T, Lan F, Lu X, Dai L, Liu Y, Yin H. Astragaloside IV enhances diabetic wound healing involving upregulation of alternatively activated macrophages. Int Immunopharmacol. 2016;35:22-8.

26. Gao LN, An Y, Lei M, Li B, Yang H, Lu H, Chen FM, Jin Y. The effect of the coumarin-like derivative osthole on the osteogenic properties of human periodontal ligament and jaw bone marrow mesenchymal stem cell sheets. Biomaterials. 2013;34:9937-51.

27. Wang J, Ma J, Gu JH, Wang FY, Shang XS, Tao HR, Wang X. Regulation of type II collagen, matrix metalloproteinase-13 and cell proliferation by interleukin-1 beta is mediated by curcumin via inhibition of NF-kappaB signaling in rat chondrocytes. Mol Med Rep. 2017;16:1837-45.

28. Behbahani ES, Ghaedi M, Abbaspour M, Rostamizadeh K. Optimization and characterization of ultrasound assisted preparation of curcumin-loaded solid lipid nanoparticles: application of central composite design, thermal analysis and X-ray diffraction techniques. Ultrason Sonochem. 2017:38:271-80.

29. Zhao Z, Li X, Li Q. Curcumin accelerates the repair of sciatic nerve injury in rats through reducing Schwann cells apoptosis and promoting myelinization. Biomed Pharmacother. 2017;92:1103-10.

30. Wang N, Liu H, Li X, Zhang Q, Chen M, Jin Y, Deng X. Activities of MSCs derived from transgenic mice seeded on ADM scaffolds in wound healing and assessment by advanced optical techniques. Cell Physiol Biochem. 2017:42:623-39

31. Bi B, Schmitt R, Israilova M, Nishio H, Cantley LG. Stromal cells protect against acute tubular injury via an endocrine effect. J Am Soc Nephrol. 2007;18:2486-96

32. Voswinkel J, Francois S, Simon JM, Benderitter M, Gorin NC, Mohty M, Fouillard L, Chapel A. Use of mesenchymal stem cells (MSC) in chronic inflammatory fistulizing and fibrotic diseases: a comprehensive review. Clin Rev Allergy Immunol. 2013;45:180-92.

33. Reitamo S, Remitz A, Tamai K, Uitto J. Interleukin-10 modulates type I collagen and matrix metalloprotease gene expression in cultured human skin fibroblasts. J Clin Invest. 1994;94:2489-92.

34. Schievenbusch S, Strack I, Scheffler M, Wennhold K, Maurer J, Nischt R, Dienes HP, Odenthal M. Profiling of anti-fibrotic signaling by hepatocyte growth factor in renal fibroblasts. Biochem Biophys Res Commun. 2009;385:55-61.
35. Zanone MM, Favaro E, Miceli I, Grassi G, Camussi E, Caorsi C, Amoroso A Giovarelli M, Perin PC, Camussi G. Human mesenchymal stem cells modulate cellular immune response to islet antigen glutamic acid decarboxylase in type 1 diabetes. J Clin Endocrinol Metab. 2010;95: 3788-97.

36. Chen FM, Shelton RM, Jin Y, Chapple IL. Localized delivery of growth factors for periodontal tissue regeneration: role, strategies, and perspectives. Med Res Rev. 2009;29:472-513.

37. Yao H, Chen Y, Li S, Huang L, Chen W, Lin X. Promotion proliferation effect of a polysaccharide from Aloe barbadensis Miller on human fibroblasts in vitro. Int J Biol Macromol. 2009;45:152-6.

38. Shang F, Ming L, Zhou Z, Yu Y, Sun J, Ding Y, Jin Y. The effect of licochalcone A on cell-aggregates ECM secretion and osteogenic differentiation during bone formation in metaphyseal defects in ovariectomized rats. Biomaterials. 2014:35:2789-97.

39. Fong CY, Gilan O, Lam EY, Rubin AF, Ftouni S, Tyler D, Stanley K, Sinha D, Yeh $\mathrm{P}$, Morison J, et al. BET inhibitor resistance emerges from leukaemia stem cells. Nature. 2015;525:538-42.

40. Ren G, Chen X, Dong F, Li W, Ren X, Zhang Y, Shi Y. Concise review: mesenchymal stem cells and translational medicine: emerging issues. Stem Cells Transl Med. 2012;1:51-8.

41. von Bahr L, Batsis I, Moll G, Hagg M, Szakos A, Sundberg B, Uzunel M, Ringden O, Le Blanc K. Analysis of tissues following mesenchymal stromal cell therapy in humans indicates limited long-term engraftment and no ectopic tissue formation. Stem Cells. 2012;30:1575-8.

42. Wang Y, Chen X, Cao W, Shi Y. Plasticity of mesenchymal stem cells in immunomodulation: pathological and therapeutic implications. Nat Immunol. 2014;15:1009-16.

43. Lee DE, Ayoub N, Agrawal DK. Mesenchymal stem cells and cutaneous wound healing: novel methods to increase cell delivery and therapeutic efficacy. Stem Cell Res Ther. 2016;7:37.

44. Hannoush EJ, Sifri ZC, Elhassan IO, Mohr AM, Alzate WD, Offin M, Livingston $\mathrm{DH}$. Impact of enhanced mobilization of bone marrow derived cells to site of injury. J Trauma. 2011;71:283-9.

45. Boehler RM, Graham JG, Shea LD. Tissue engineering tools for modulation of the immune response. Biotechniques. 2011;51:239-40.

46. Ren G, Zhang L, Zhao X, Xu G, Zhang Y, Roberts Al, Zhao RC, Shi Y. Mesenchymal stem cell-mediated immunosuppression occurs via concerted action of chemokines and nitric oxide. Cell Stem Cell. 2008;2:141-50.

47. Ma S, Xie N, Li W, Yuan B, Shi Y, Wang Y. Immunobiology of mesenchymal stem cells. Cell Death Differ. 2014;21:216-25.

48. Nemeth K, Keane-Myers A, Brown JM, Metcalfe DD, Gorham JD, Bundoc VG, Hodges MG, Jelinek I, Madala S, Karpati S, Mezey E. Bone marrow stromal cells use TGF-beta to suppress allergic responses in a mouse model of ragweed-induced asthma. Proc Natl Acad Sci U S A. 2010;107:5652-7.

49. Ortiz LA, Dutreil M, Fattman C, Pandey AC, Torres G, Go K, Phinney DG. Interleukin 1 receptor antagonist mediates the antiinflammatory and antifibrotic effect of mesenchymal stem cells during lung injury. Proc Natl Acad Sci U S A. 2007;104:11002-7.

50. Liu Y, Wang L, Kikuiri T, Akiyama K, Chen C, Xu X, Yang R, Chen W, Wang $S$, Shi S. Mesenchymal stem cell-based tissue regeneration is governed by recipient T lymphocytes via IFN-gamma and TNF-alpha. Nat Med. 2011;17:1594-601

51. Allen JE, Sutherland TE. Host protective roles of type 2 immunity: parasite killing and tissue repair, flip sides of the same coin. Semin Immunol. 2014;26:329-40.

52. Furukawa S, Moriyama M, Tanaka A, Maehara T, Tsuboi H, lizuka M, Hayashida JN, Ohta M, Saeki T, Notohara K, et al. Preferential M2 macrophages contribute to fibrosis in IgG4-related dacryoadenitis and sialoadenitis, so-called Mikulicz's disease. Clin Immunol. 2015;156:9-18.

53. Murray LA, Chen Q, Kramer MS, Hesson DP, Argentieri RL, Peng X, Gulati M, Homer RJ, Russell T, van Rooijen N, et al. TGF-beta driven lung fibrosis is macrophage dependent and blocked by serum amyloid P. Int J Biochem Cell Biol. 2011;43:154-62

54. Knipper JA, Willenborg S, Brinckmann J, Bloch W, Maass T, Wagener R, Krieg T, Sutherland T, Munitz A, Rothenberg ME, et al. Interleukin-4 receptor alpha signaling in myeloid cells controls collagen fibril assembly in skin repair. Immunity. 2015:43:803-16.

55. Spiller KL, Koh TJ. Macrophage-based therapeutic strategies in regenerative medicine. Adv Drug Deliv Rev. 2017;122:74-83. 
56. Smith TD, Nagalla RR, Chen EY, Liu WF. Harnessing macrophage plasticity for tissue regeneration. Adv Drug Deliv Rev. 2017;114:193-205.

57. Sadtler K, Estrellas K, Allen BW, Wolf MT, Fan H, Tam AJ, Patel CH, Luber BS, Wang $\mathrm{H}$, Wagner KR, et al. Developing a pro-regenerative biomaterial scaffold microenvironment requires Thelper 2 cells. Science. 2016;352:366-70.

58. Badylak SF. Tissue regeneration. A scaffold immune microenvironment. Science. 2016;352:298.

59. Badylak SF. The extracellular matrix as a biologic scaffold material. Biomaterials. 2007;28:3587-93

60. Song JJ, Ott HC. Organ engineering based on decellularized matrix scaffolds. Trends Mol Med. 2011;17:424-32.

61. Quarti A, Nardone S, Colaneri M, Santoro G, Pozzi M. Preliminary experience in the use of an extracellular matrix to repair congenital heart diseases. Interact Cardiovasc Thorac Surg. 2011;13:569-72.

62. Sicari BM, Johnson SA, Siu BF, Crapo PM, Daly KA, Jiang H, Medberry CJ, Tottey S, Turner NJ, Badylak SF. The effect of source animal age upon the in vivo remodeling characteristics of an extracellular matrix scaffold. Biomaterials. 2012;33:5524-33.

63. Zheng Z, Zhang X, Dang C, Beanes S, Chang GX, Chen Y, Li CS, Lee KS, Ting $\mathrm{K}, \mathrm{Soo} \mathrm{C}$. Fibromodulin is essential for fetal-type scarless cutaneous wound healing. Am J Pathol. 2016;186:2824-32.

64. Larson BJ, Longaker MT, Lorenz HP. Scarless fetal wound healing: a basic science review. Plast Reconstr Surg. 2010;126:1172-80.

\section{Submit your next manuscript to BioMed Central} and we will help you at every step:

- We accept pre-submission inquiries

- Our selector tool helps you to find the most relevant journal

- We provide round the clock customer support

- Convenient online submission

- Thorough peer review

- Inclusion in PubMed and all major indexing services

- Maximum visibility for your research

Submit your manuscript at www.biomedcentral.com/submit 